\title{
The Impact of Technological Developments on the Contextual Imperatives of Performance in the Delivery of Verbal Folklore
}

\author{
Francis Mowang Ganyi \\ Department of English and Literary Studies, University of Calabar, Calabar
}

\begin{abstract}
Folk material delivery, particularly storytelling and other folk arts like folk dance and drama, in the past suffered proper perception and in-depth analysis because they were difficult to comprehend or deliver textually or even reduce to printed text and still maintain their efficacy. For this reason, they suffered from lack of proper analysis. However, today's technological world now subjects them to rigorous scrutiny due to the sophistication of electronic media like video tapes and cameras which are employed in the recording of performances. This development has largely helped to highlight the intricacies of contextually centered performances which properly aggregate to the artist his central role in the perception of oral narratives. With the development of these electronic machines, contextual performance studies are now gaining grounds while contextual theories are enunciated and emphasized in the study of folklore all within the collaborative fields of Sociology, Anthropology and Literature. However, the usefulness of these technological developments notwithstanding, their impact on the effective delivery of folk narratives within the actual context of production i.e. within performance, still leaves much to be desired. This is obvious from the fact that the exposure of the artist or performer to the glare of klieg lights or even the presence of the camera in a performance session changes the entire atmosphere of the performance. Of course, it can be argued that all of these reactions constitute the totality of the performers' perception of his milieu or the changing circumstances in society which impacts on the delivery of folk material. The vital questions that still remain are, does the artist respond to technological development or to traditional societal demands of shaping the consciousness of the growing youthful population and Is this technology impacting positively or negatively? These are pertinent questions because despite the fast developing cosmopolitan status of African countries, the bulk of the population still reside in traditional societies that lay emphasis on traditional values, norms and practices in the education of their youths. The artists' role should therefore be to propagate and portray these cherished values rather than allow for the bastardization of culture through profuse responses to technological demands that impact negatively on the perception of youths. Watch, for instance, the impact of television viewing on children in the metropolis and their responses to elders or parental attempts to control their perception of life. Using the Bakor society as an example therefore, this paper stresses the need for an emphasis on contextual delivery of folk materials that root for tradition rather than those that emphasize blind modernization which kills respect for traditional values.
\end{abstract}

Keywords: Traditional values, Performance Context, Folklore, Technology.

\section{Introduction:}

In the $21^{\text {st }}$ century, the realization, perception and delivery of folk material has changed considerably. Following from these have been new perspectives fostered by equally new theoretical and technological advancements that impact greatly on folklore delivery. Right from the nineteen sixties to date, a new emphasis developed highlighting the contextual study of folk material and fostered by the Parry/Lord Oral formulaic theory which has eventually led to what has now come to be known as the "contextual theory" on the study of folklore. As a result, emphasis has shifted from "text orientation," which many folklorists believed was responsible for the categorization of folklore as fossils because of their insistence on pastness or their survivalist orientation towards folk material collection and analysis. Folklore theories now centre on the dynamic character of societies and consequently of folk material itself thus necessitating a contextual approach which is expected to portray the contemporary relevance of folklore to evolving societal needs of the societies that produce it. Text oriented theories, it is believed, were too narrow and conservative to recognize this dynamism in oral tradition and so an internet contributor on new approaches to folklore studies has clarified the contextualist position by observing that

- ...Contextualists insist that the concept of folklore apply not to a text but to an event in time in which a tradition is performed or communicated. Therefore the whole of performance or communicative act must be recorded. The collector can no longer simply write down or tape record texts for the text is only part of each unique event... Literary and ethnographic methods which complement each other, and [an] emphasis on rigorous field work are considered keys to successful contextual studies. 
Mary Magoulick (2012) adds to this changing concept by telling us that

- $\quad .$. the study of folklore has changed over time. Previously, scholars believed that the subjects (texts or culture) were decaying or disappearing but now we consider folklore and culture as efficacious and meaningful processes within our present reality.

And so we must recognize

- ...Performance [as] the major theory used within folklore studies today,

Which necessitates the encouragement of

- ...field work [that] connects folklorists to the community and provides contextual knowledge for textual analysis

What this implies is obvious. It changes the perspective from straight forward or simple linear narration to a contextual performance orientation that places emphasis on the event and its relevance to the community that carries it out. This is, infact, a multidimensional performance orientation that contextualists emphasize when they reject the consideration of the text above the context of delivery. For this reason, one is bound to think or believe that modern multimedia electronic gadgets will best capture the performance context or environment. The situation, however, is not exactly true as these equipment, particularly the tape recorder which is easier to handle, still fails to capture the intricacies of the performance context in terms of the extra linguistic resources available to the performer in folklore delivery. The video recorder attempts to solve this problem to a large extent but still falls short because its sophisticated technology imposes extraneous demands on the performer and audience in the context of performance as their consciousnesses are directed elsewhere rather than on the business of performance. The performance itself may, infact, not even be understood beyond the immediate context of the live rendition if the dynamic interface between performer and audience is not well focused. Dan Ben Amos (1976) has therefore observed that

- ... For years we have known that the written page is but a pale reproduction of the spoken word, that a tale hardly reflects that, no matter how carefully we record oral texts, much is left unprinted, [and] even more is not understood.

Only a contextual approach attempts a detailed recording of the narrative events as they occur in the context or performance and so the internet contributor again argues that

- ...since contextualists' insights go beyond the text into the holistic aspects of a folkloristic event - be it a storytelling event or a dance performance - they take into consideration the multidimensional paradigm of the context of such an event. For instance, a story telling event to the contextualist means, besides the text, the narrator, the occasion, the style of narration, the audience, the interaction between the narrator and the audience and the entire cultural background which forms the event [must be considered]... this means recording the text and the whole circumstances... in which the text was delivered by the narrator and received by the audience [which] entails the use of sophisticated video equipment for capturing the contextual essence of the event.

Herein lies the problem for the video recorder is expected to highlight the intricacies of the contextually centered performance and its relevance to the society that produced it. The video recorder should explicate the verbal aesthetics, the artistic utilization and manipulation of the verbal and extra verbal resources available to the artist during the performance. This is a very intricate expectation of the recorder or decoder of the performer's message particularly if the recorder is alien to and so does not speak the language or understand the culture of the community he is working with. Even when he does know the culture as is expected of today's researcher, the circumstances or personal motivations of the performer that enhance variability of performances need to be considered. All of these require personal interaction between performer and recorder which cannot be captured in the recording. Furthermore, the performer/audience relationship that enlivens the dynamics of rendition and spur the creative impulse of the performer to move the tale forward cannot be recorded. The recorder needs to observe and understand this rapport which is established because the performer and his audience are operating within the same aesthetic principles of literary production and comprehension. What point is being made here is that the perception of the oral narratives - folk dances, song composition, folk drama and other artistic artifacts - all depend on the skills and perception of the artists responsible for the creation of these items and on the contexts of performance where traditional imagery is succinctly utilized to capture and portray the meaning and relevance of the folk items to the community of production. The perception also depends on the effective intercourse between the oral artist and the audiences who are the judges and critics of the mode of delivery of these folk products. To achieve an effective delivery, therefore, the oral artist responsible for the presentation of these folk items, must have recourse to the use of traditional multimedia resources that support and enhance the delivery of his materials as dictated by the aesthetic principles governing production and reception of same in his community. In a particular community, the peculiar multimedia resources may include among others, verbal embellishment, histrionics, musical instruments, props and costumes, all of which enhance spectacle creation and heighten aesthetic pleasure and entertainment. 
Furthermore, in a given society, aesthetic pleasure is achieved only when shared conventions of performance are properly utilized to project and portray the entire gamut of society's literary patterns and practices which underlie and embody the production and appreciation of their cultural norms, values and interactive procedures among the groups and individuals involved.

\section{The Contextual Imperative Of Performance And The Nigerian Environment}

In traditional African societies generally and Nigeria in particular, the production and delivery of folk materials or culture and the preservation of cultural norms and practices as well as history of cultural entities has for long remained the prerogative of traditional artists or griots in the case of verbal forms, whose medium is essentially oral as is always the case with pre-literate cultures at the initial stages of development. Folk or oral performances remain the major modes or avenues for the articulation of recreational, entertainment, pedagogical or any other functional purposes in the traditional societies. Performance sessions, for verbal forms, which are paramount in every traditional African society, are usually organized at twilight or even night time except in few cases like the Mande of Sierra Leone as observed by Amadu Wurie Khan (2009) where there is insistence on good light for performance sessions to take place. Most Nigerian communities that I know of (Igbo, Hausa, Yoruba) prefer night time when the day's chores are done with for obvious reasons that no one lives by storytelling principally and most story tellers are farmers. Moreover, darkness helps to mystify or sustain the air of esotericism or wonder often associated with the renditions. In these narrative sessions, the traditional artist assumes responsibility for communal cultural authentication and maintenance of cherished values. Perception of society's cosmic, social and political life is through the consciousness of story tellers and the narrative protagonists they create as embodiments of societal norms and values. In African society, all items of folklore, particularly verbal lore, are conceived of as embodiments of cultural characteristics peculiar to a people which serve as the means of authenticating the collective existence of these cultural entities. Folklore, therefore, serves as a unifying force within the various tribal units and even between different units that share certain common affinities. Given this scenario, the artist's place or task as a molder of traditional opinion for the sustenance of collective experiences of the community becomes onerous and must not be subject to too many external influences or be left in the hands of alien cultural intrusions that can detract from his consciousness of his role in society. To ensure that the artist operates within the limits of acceptable societal expectations, the artist is subject to audience sanction through approval or disapproval of his renditions - approval if societal values are adequately represented and, disapproval if he deviates from aesthetic standards known and acceptable to society. The artist is, therefore, under strict audience surveillance, to effectively delineate his performance to achieve the transfer of desirable cognitive experience that will positively impact on society. The artist requires equally adequate performance contexts within which to effectively utilize traditional multimedia resources like improvisation, mimicry and/or performer/audience interaction to aid the establishment of a rapport between the artist and his society which emphasizes the contextual imperative of performance. The role of the audience as prescriptors and critics of aesthetic standards is also important for the production, realization and perception or reception of the aesthetic implications of folklore or the collective experiences of the people. Among the Bakor people of Ogoja Local Government Area of Cross River State and their Igbo counterparts of Anambra, Imo and Abia states as well as the Tiv of Benue State all in Nigeria, audience appreciation of the performer's skill at manipulation of linguistic and extra linguistic resources within the context of performance is the most vital component of the audiences' acceptance of the final product i.e. the folklore and what it portends in the society. This appreciation also stands as the audiences' assessment of the performer's skill and artistic excellence. Audience applause animates the entire performance and enhances societal perception of the value of the folk material being delivered.

\section{The Impact Of Modern Technology On Oral Renditions In Performance Contexts}

Within the paramount relevance of the performance context as the major means by which communal or tribal folklore can be adequately appreciated, one now attempts to view the impact of such external influences or intrusions like modern multimedia resources which include radio, TV, video cameras, tapes recorders and recently GSM phones on performance contexts that are invariably structured and patterned after the peculiar aesthetic standards, experiences and philosophical world view of a particular cultural environment or milieu. Since we have already observed that the recording of the totality of folklore or experience in a contextually determined performance requires the use of sophisticated video equipment for capturing the contextual essence of the event, the questions that readily come to mind include

a) How many folklorists - artists inclusive - within the African environment are in a position to afford or even if they can afford, readily deploy their resources to the purchase of such sophisticated equipment to capture contextual performances which they are part and parcel of? 
b) How much patience do real accomplished performers exhibit with recorders or the mass media in actual performance situations? Recorders are seen as impediments to the flow or movement of the aesthetics of rendition in a contextually determined performance, and

c) Very importantly too, to what extent do artists and even audiences keep to the norms of performance when faced with such sophistication which is alien to the culture or performance context. Many artists would pander to commercial or political exigency at the expense of aesthetic considerations and produce unexpected results.

It is generally known and accepted that there is a marked difference between "recitation" or simply "narration" of stories and "performance" of same. The narrator recites the stories, mostly verbatim without any conscious changes on the fabric of the story because he has no perception of any demands on his recitation. The performer, on the other hand, is conscious of his responsibility to society as modeler of the collective conscience and morality of his people as well as projector of communal norms and values. He stands to society as the tale to the performance. He can be directed by the audience just as the tale can be varied by the performer according to the demands of the performance context or occasion for performance. To achieve this contextual variability, the performer's subtlety and artistic skills impact on the narrative thus moving society's consciousness towards the achievement of goals aimed at societal advancement. The performance becomes in the words of Dell Hymes (1975) "Overt Behavior [on the part of the performer] as a realization of an underlying meaning [of culture] on the part of the speaker." Without a contextually determined performance, where the performer responds to the demands of the audience, the recite subverts the social import of the narratives while at the same time killing the aesthetic content that accompanies accomplished performances. The $21^{\text {st }}$ century is a highly sophisticated age in which technological advancements are greatly impacting on every facet of human life thus the general view that "the world is fast becoming a global village," where everyone can easily tap into another's life and experiences. Culture and folklore no longer seem to be unique distinguishing features of ethnic entities. Computer memory has largely limited the reliance on human memory or rote-memorization for the delivery of folklore items to the extent that human memory and human experiences are now greatly impaired or almost superseded by artificial points of view fed to audiences through depersonalized objects that include T.V. sets, radio sets, home videos and G.S.M phones e.t.c. All of these roll out material that is fabricated for targeted achievements in audiences that are expected recipients of the messages. Such audiences have no input whatsoever in the formulation of the messages and expected achievement unlike in contextually determined performances where the audience determines what they want.

The $21^{\text {st }}$ century technologically compliant world typified by the development of sophisticated multimedia equipment permits no interactive participation in the formulation and delivery of folk culture on the part of the audience. The audience is essentially a passive and redundant force in today's communicative process. The immediate participatory and interactive environment of traditional discourse that enlivens communication and enhances closeness in inter personal relationships characteristic of traditional societies is lost. Along with this loss is the de-emphasis on traditional modes of discourse like the use of proverbs, riddles, witticisms and tongue twisters which served as traditional pedagogical resources. Modern technological advancements on communication or multimedia resources of the $21^{\text {st }}$ century have almost completely obliterated the interactive perception and reconciliatory authentication of experiences that make for societal cohesion as was the case with folk narrative discourse in the past where a performer interacted with a listening audience through tales. With this kind of inter-personal relationship, experiences were shared and strife or conflict ameliorated for the enhancement of cultural co-existence. In the absence of the inculcation of traditional moral values made possible by the de-emphasis on folklore practices, the growing youthful population is vastly unable to perceive the values of tolerance and communal co-existence hence society is open to conflict and violence which is evident in all facets of Nigerian life today. Today's Nigerian youth is rather exposed to intense individualization which breeds introverts. The prevalence of G.S.M networks and home videos have also tended to close up the youthful population and prevents them from the most desired interaction that would enable them to learn more about other people's predilections. This kind of introversive individualism prevailed in early renaissance Europe that favored the outburst of violence and conflict during the Reformation.

The dual (positive and negative) influence of electronic media on the development of traditional forms of entertainment and other folkloristic productions in Mali is also succinctly captured by Mamadou Diawara (1994) who posits that Malian

- $\quad$...ancient music, pleasing to historians and anthropologists, is undergoing a complete transformation. An essential but hardly examined feature is the influence of electronic media: radio, tape recording and television.

To this extent, one can ask, like Diawara, the extent to which electronic media has positively aided the transformation of traditional society towards achievement of the process of globalization. Diawara argues that in Mali, the emergence of Electronic media coincided with the rearrangement of the social aristocratic order which broke the hold of the traditional griots as entertainers and spokesmen of the feudal lords and necessitated the 
movement of the griots into the city where they got caught up with new demands and the entertainment of a new class of audience. The result was that the village artists or griots "no longer played the role of advisor, spokesman, historian, story teller, or private musician for their descendants." The development of electronic media invariable destroyed the age old role of the Malian griots of the famous Sundiata epics of old Mali. All of us know the fame of these griots as traditional court historians and repositories of the folklore of the old Mali Empire. The traditional artist or griot now has a new master, the creation of the Western Literary Aristocrat for whom the griot now sings praises. This, however, is limited in scope and acceptability because the proud traditional artist stands his grounds in the rural areas and refuses to be consumed by the new wave of modernism and so still asserts his superiority over his cosmopolitan rival who has become commercialized and panders after political patronage. Diawara's incorruptible traditional artist, Kamissoko, therefore asserts in the face of challenges by nitwits who claim to be accomplished artists thus

- ... this is why I will narrate what I know of the history of Massalens... yes, what I know of that history, I

will tell you in a story which does not have lies, nor flattering words... any conversation we have or any

word coming from my mouth, from Wa Kamissoko, can be spread across the four corners of the country. If

there is anyone who thinks my telling is just lies, ask them and ask me, and sit us down in the same place so that we can debate. Yes, I am the great griot of Mandem..

Nothing can be more of an authoritative assertion of Kamissoko's command of his audience and the integrity of his profession. The Malian traditional artist knows his worth in his milieu as opposed to the lies and flattery of those who pander up to the modern mass media for commercial gains. His is the authoritative word of mouth that spreads across the four corners of the country uninterrupted by modern mass media. Kamissoko's assertion is an indirect warning that what we must be careful about is allowing the traditional artist to be removed from his environment where he is the voice of the people that speaks the truth and being transposed to modern multimedia practices of propaganda aimed at selling what is undesirable to the people. The moment this happens, folklore, along with the values of truthfulness and humility, sacrosanct to the traditional environment will be lost or subjected to the same propaganda prevalent in our modern radio and T.V stations. The result is that society will totally be open to disillusionment, despair and frustration. This is what seems to be happening already in Nigeria today. Diawara further notes that today's Malian griots have lost their prestige to the electronic media practitioners because they are no longer loyal to their traditional patrons. Says Diawara

- ... The new artist communicates with his listeners and his public by recordings or sound waves and still

refers back to... the show business environment. The audiences praises, ignores, or blandly accepts the productions; show business reacts by agreeing to finance the next public performance [or] the next recording. The direct personal contact the artist formally had with his peers [or traditional audience who dictate the taste] and the accompanying responsibility and restraint have faded in favour of new relationships and [new] responsibilities.

This is the prevalent atmosphere of the $21^{\text {st }}$ century that pervades the Nigerian environment and does not augur well for the maintenance or continuity of folk traditions in most African nations. What is happening is that the collection, retention, propagation and proper apprehension of folklore are subject to foreign media dictates that can only be conceived of as bastardizations of our folk traditions. They are certainly far from the traditional folk culture presented in contextual performance situations that emphasize audience/performer interaction. What artists do today is to sing praises to high political office holders and multi-national businessmen for financial gains while mortgaging the conscience of their traditional societies. If the need to present a fair picture of our folklore overrides commercial and personal interests, our artists must be encouraged by us the acclaimed folklorists to shun mediocre out of performance context renditions to produce edifying folklore that can stand against the barrage of the sophistication of electronic media and what it offers. After all, all that glitters is not gold. Modern multimedia should be made to copy from or buy the concrete artifacts of traditional artists, who, like Kamissoko, refuse to face the glitter of city life or pander to political demands so that they can produce significant folklore for our nations individually and the continent at large. We emphasize this because the traditional artist who operates within the contextual imperatives of performance is the true recorder of folklore. $\mathrm{He}$ is the means by which information of all kinds is explicitly and implicitly recorded, evaluated and transmitted using the aesthetic standards or criteria established by the traditional community and passed on to successive performers within that environment. By so doing, we maintain societal ethics and performance aesthetic standards for every tribal group and the nation. We also recognize the resourcefulness of the oral artists, who, in performance context, rework the fabric of traditional society's and consequently the Nations collective folk experiences through the multiple application of traditional multimedia resources at their disposal to create aesthetically pleasant folklore to attract local and foreign audiences. These are the repositories of our folklore whose products we must prioritize in order to appreciate the uniqueness of Nigerian and even African Folklore.

Unfortunately, the future of traditional artists and the contextual delivery of folklore seems to be very bleak in most if not all African nations. We have already observed that most African nations are now predominantly 
exposed to audio visual mass media forms and practices of entertainment, including very recently, cell phones which highly threaten the continuous reliance on traditional multimedia forms of cultural transmission. We have also noted the experience of Malian griots. Amadu Wurie Khan (2009) speaks of the Sierra Leonean story tellers experience of exposure to modern mass media forms and their effect on the traditional cultural practices of storytelling and observes that

- ...This exposure [to modern mass media practices] has placed greater demands on Themne oral art practitioners to make their material and performances more attractive to the clientele, particularly to the younger generations... The latter constitutes the larger part of the Themne population, and, as the school age group, is exposed to literate media entertainment forms, it is increasingly likely to lose interest in traditional folklore practices as has been the case with storytelling in post war technological societies.

Though one observes that the Sierra Leonean exposure has the advantage of improving the skills of the artists, what one fears is the consequent loss of interest in traditional folklore practices. If this happens, what then will be said to be the identity of this nation in the future. It does not end there. Also speaking on the potential threat to traditional media forms of folklore transmission by electronic or modern mass media forms, Aaron Mushengyezi (2003) observes that in Uganda

- $\quad$... The advent of new technology is a potential threat to the use of indigenous media among younger generations of Ugandans.

But Mushengyezi underscores the point by arguing that the situation arises because of

- ...a combination of widespread non-literacy and poverty among Ugandans [which] permits indigenous media to continue to be a viable means of public communication.

In accepting the learned scholars postulation that the advent of new technology is a potential threat to the use of indigenous media, I would like to part ways with him in his position that poverty and illiteracy permit indigenous media to continue to be viable and posit instead that it is not so much illiteracy and poverty that sustain the viability of indigenous media as a veritable means of public communication but the fact that indigenous media forms of folklore transmission are more vibrant and attractive because of the interpersonal relationships they foster or encourage. Also the fact that the artist, through the use of contextual imperatives of improvisation and histrionics enliven the interaction between performer and audience while making the transfer of cognitive experience a more pleasurable exercise. The demise of this contextual imperative of performance in the transmission of folklore in many African countries is worrisome to this writer because it portends the dearth of culture in these nations if nothing is done to refocus attention on traditional forms of communication. To stem this dangerous loss of interest in folklore, this writer advocates a sustained and consistent emphasis on traditional multimedia forms of folklore transmission that can rekindle this dying interest on folk material production and transmission. Such rejuvenating paradigms include,

a) The insistence on contextual performance situations in traditional societies that adequately portray the stylistic features of folklore delivery.

b) The encouragement of performers particularly song composers and story tellers whose performances serve as pedagogical and satirical modes of societal control and advancement.

c) The need for educational institutions to be encouraged to include oral literature courses in their curricula for the enlightenment of younger generations on our folk ways, and

d) The encouragement of "resident" artists to create verisimilar situations to performance contexts in traditional environments for scholars and researchers to visit with their students.

They may be other viable options but the fact remains that if something is not done fast enough to stem the trend of this erosion of interest in traditional folk practices, Western ideas which are fast taking root to the detriment or exclusion of our own folklore and traditions will soon obliterate this folklore which we so much cherish. From the above, one can surmise that our folklore is at the brink of extinction as a result of Western propaganda propagated through modern audio visual mass media which, of course, does not achieve the same purpose and certainly lacks the same vibrancy and effectiveness in folk delivery as contextual performance situations that emphasize performer/audience contact. In the contextual imperative of performance in folk delivery, the onus is on the artist and his audience to ensure that they adequately utilize the contextual imperatives of performance to enhance the transmission of folk material for the edification and the upliftment of society. The more we neglect performer interactive models of folk delivery in favor of modern audiovisual mass media forms, the more we kill the interest of the younger generations in these traditional interactive models and consequently the greater the risk of extinction of our folklore. Very soon, our villages, which are the centers of cultural production, maintenance and transmission, will soon become cosmopolitan cities with the penetration of modern mass media resources; our Elders will die out or lose touch with our folk practices and our nations will become Western neo-colonialist states that sing the triumph of literary writing.

Before I am misjudged or misinterpreted, let me hasten to point out here that I am not an advocate of the total exclusion of modern mass media resources or any other form of technological development from the processes of folklore transmission. Looking at the Sierra Leonean and Malian experiences, one notices that there are 
positive sides to the use of modern mass media in the delivery of folklore. In Mali, though the traditional griot lost his place in the scheme of things, other avenues like modern recording studios and the developments of new brands of musical ensembles were open to the artist to explore. In Sierra Leone, Wurie Khan observes that the intrusion of electronic media enhanced the improvement of the artists' modes of delivery of folklore because of the extra demands on aesthetic pleasure imposed on them. These are positive sides to the advent of modern technology in the field of folklore. Infact, we had earlier observed that sophisticated recording equipment can enhance a better view of the contextual imperative of performance. My advocacy, therefore, is for an emphasis on interactive models of performance that emphasize context over text and audience/performer relationship. This way, the vibrancy of folk material delivery is enhanced while too much reliance on modern mass media resources is discouraged. The argument of modernism, increasing literacy and global interdependence of cultures has often been advanced as major reasons for the non-reliance on the oral media for the transmission of folk material since everyone is expected to tap into other people's values in a global environment. The fault in this argument, however, is that not everybody is literate even in the so called international languages. English or French Languages are useless to an illiterate Bakor Elder in Ogoja Local Government Area of Cross River State. In folklore transmission, language may not be too much of an impediment since actions speak louder than words as we all accept. What is happening to us as Africans, however, is a lack of definite objectives which should define our needs and which, in turn, lead to the poor leadership syndrome that characterizes all African nations opening them up to political economic and cultural neo-colonialism; and the lack of a definitive cultural policy that should sustain folklore production, maintenance and delivery based on adequate theoretical frameworks that are environmentally compliant. What technological advancement and the widespread and sometimes uncritical acceptance of Western education and its attendant values is doing to many African societies is the exposure to and proliferation of modern multimedia methods of communication which, if unchecked or unreversed for equal emphasis on cultural emancipation, will lead to the eventual obliteration of African oral narratives and the attendant folkloristic values they portend in favor of Western values represented by literary writing as the only mode of transmission of ideas for educational or other purposes. The fear is that the loss of oral traditions to modern multimedia constructs would presage the loss of the qualities, ideas and values which are better expressed or transmitted orally through interpersonal relations. This would also mean the dearth of several African communities which are predominantly illiterate in literary writing and the demise of vibrant and living folk traditions.

Before this happens, however, the African traditional artist or performer can still be relied upon, within the imperatives of a contextually defined performance, to perpetuate the redirection and remolding of the consciousness of younger generations within the dictates of the aesthetic principles that define folklore generation and transmission in a particular community. He is still the focus of the moral foregrounding of the traditional narratives' messages and their relevance to society. If performances are articulations of folk values as well as aesthetic standards within societies, then the performer cannot be isolated from the composition and transmission of these folk narratives. Consequently, if the performer must be given his due credence in the oral narrative scheme, it cannot be outside the contextual performance imperative in the transmission of folklore where he can feature at his best in the interactive sessions between performer and audience in the job of societal stabilization through folklore delivery. To bring this home, perhaps, the experience of Bakor community will suffice here as an example of the negative influence of excessive reliance on modern mass media resources. The Ekajuk community, one of the eight Bakor communities in Ogoja and Ikom Local Government Areas of Cross Rover State possesses a very closely knit cultural background. Folklore or cultural transmission is enhanced through the use of traditional multimedia resources of linguistic improvisation, embellishment and histrionics prevalent in contextual performance situations. In this regard, parental control, molding of consciousness and perception of the environment is the preserve of Elders and accomplished performers. In this scheme, also, society is characterized by absolute respect for age and seniority as well as strict adherence to culturally established norms and values. However, like every other developing society, this Ekajuk society is gradually being exposed to formal Western education and its attendant Western values replicated in the mass media resources. Literacy has considerably widened the scope of interaction and acceptance of these Western values which in most cases are wrongly perceived and applied like the "sagging syndrome." Ekajuk society is now vastly prone to the penetration of technologically advanced creations like radio and T.V sets, video tapes and cameras, G.S.M phones e.t.c. all of which expose young ones to modern mass media influences some of them undesirable. The overall impact of this exposure is the very high rate of promiscuity and deviant behavior to which youths are exposed. Loitering has become prevalent during school hours while children roam the village in search of places to watch video films. This is even more prevalent in many Nigerian cities. At night, little children keep late nights watching video films and European league matches yet none is interested in the African Cup of Champion Clubs. There is also prevalent general disrespect for age and seniority which was never tolerated in the past while values which used to be inculcated through storytelling and other folk practices are fast degenerating or lost completely. Storytelling sessions are now replaced by home videos and disco dance 
sessions. This writer was once jolted by a little child he heard singing "disco no pants" which is apparently an adulterated form of a modern record but which adulteration is reminiscent of the present level of depravity formally unheard of among children of that age bracket. The impression that has been created is that people usually went to Disco without pants for sexual orgies. It was also shocking to discover that nudity had become the vogue among young girls who allowed themselves to be put on video tapes for commercial reasons. All of these practices have become fashionable in traditional society as a result of the penetration of modern mass media equipment which are products of technological advancements and which discourage traditional modes of communication and entertainment while encouraging deviancy in traditional society. An Elder Nshor Egre Mbrayip of Blessed memory once informed this writer during a research on proverbial usage that storytelling was no longer prevalent because the traditional audience had been taken over by school and "cinema radio" which is the television set.

\section{Conclusion}

Human society unlike the animal kingdom is an extremely dynamic society that is constantly prone to changes, sometimes very drastic in the course of human existence. The changes are, however, never limited to the societies that initiated them since human society is also prone to interaction particularly in today's technologically vibrant world of globalization. Technology itself has so revolutionized all facets of human life making it subject to one form of control or other by gadgets. The effect is such that life without these gadgets immediately sounds drab and worthless. The world of entertainment even in traditional contexts has completely been taken over by electronic gadgets which have obliterated traditional forms of entertainment to the extent that their performance and evolution is eclipsed. However, despite the attractiveness of the technological "advancements," man should not be seen to be a slave to the dictates of technology. What is happening to Nigeria today tends towards enslavement of the human potential instead of its utilization. Human memory is fast being replaced by computer memory, domestic chores are performed with machines and even the exercise of the human person is carried out by machines. To some people, this may be a welcome and desirable development but subjection of the human intellect to redundancy breathes indolence and decay. Moreover, there are certain aspects of human life and existence like folklore production and delivery which are best comprehended in performance context where interaction between performer and audience participants plays an active and dynamic role in the explication and appreciation of values and their relevance to societies that produce them. Technological advancements should therefore be geared towards the explication rather than obliteration of the totality of contextual imperatives of performance to enhance a better view of folklore and traditional cultural practices that authenticate Nigerian and African cultures instead of attempting to decimate same in favour of Western cultural values.

\section{References}

[1]. Ben-Amos, Dan and Kenneth Goldstein (eds) (1975) Folklore: Performance and Communication. The Hague: Morton press.

[2]. Ben-Amos, Dan (ed) (1976) Folklore Genres. Austin: University of Texas Press

[3]. Diawara, Mamadou (1994) Production and Reproduction: The Mande Oral Popular Culture revisited by electronic media. Michigan: MPublishing University of Michigan Library.

[4]. Dorson, Richard M (ed) (1972) Folklore and Folklife: An Introduction. Chicago: University of Chicago Press.

[5]. Dundes, Alan (1964) “Texture, Text and Context.” Southern Folklore Quarterly. Vol. 28 Pp 251 - 265

[6]. Dell Hymes (1975) "Breakthrough into Performance," in Dan Ben-Amos and Kenneth Goldstein (eds) Folklore: Performance and Communication. The Hague: Morton Press Internet: Growth of Folklore Theories: An Introduction. www.ciitebooks.net/html/folkintro/ch2.html

[7]. Khan Amadu Wurie (2009) "Paradigms of Social Aesthetics in Themne Oral Performance.” Oral Tradition. Vol. 24, No. 1 Pp 143 159

[8]. Macdonald, Donald A (1972) "Fieldwork: Collecting Oral Literature." In Richard M. Dorson (ed) Folklore and Folklife: An Introduction. Chicago: University of Chicago press.

[9]. Magoulick, Mary (2012) "History of Folklore" www.faculty.de.gcsu.edu/ mmagouli/fldes.htm

[10]. Mushengyezi, Aaron (2003) "Rethinking Indigenous Media: Rituals, "Talking” Drum, and Orality as forms of Public Communication in Uganda." Journal of African Cultural Studies No. 16. Pp. $107-117$

[11]. Okoh, Nkem (1988) "Igbo Tale Collections: The Past, the Present and the Future." Kriteria. No 111, Pp 34 - 53 